Int. J. Electrochem. Sci., 13 (2018) $2206-2218$

International Journal of

ELECTROCHEMICAL

SCIENCE

www.electrochemsci.org

\title{
Surface Modification of Coal-Based Coke Powder with Pitch Powder for Lithium Ion Batteries
}

\author{
Feng Chen, Lulu Ma, Jiangang Ren, Baoxiang Gu, Jiwei Zhang, Pei Ma, Bibo Liu* \\ School of Resource and Environment, Henan University of Engineering, Zhengzhou 451191, China; \\ *E-mail: liubb2008@126.com
}

doi: $10.20964 / 2018.03 .49$

Received: 3 November 2017 / Accepted: 5 January 2018 / Published: 5 February 2018

\begin{abstract}
As we all know, most of coal-based coke powders are burned as cheap fuel or discarded directly every year, causing serious environmental contamination and enormous waste of resources. Fortunately, previous works have proved that coal-based coke powder is a promising anode material for lithium ion batteries, while the low initial coulombic efficiency and large irreversible capacity of coal-based coke powder limit its large-scale application. In this work, three kinds of surface-modified coal-based coke powders with pitch powder as the anode materials for lithium ion batteries were developed. Results showed that, compared to the samples $\mathrm{C}_{\mathrm{T}}$ (prepared with pitch powder pre-coating in toluene solution) and $\mathrm{C}_{\mathrm{A}}$ (prepared with pitch powder pre-coating in alcohol solution), the surface modification of coalbased coke powder prepared by mixing the mixture of coke power and pitch powder $\left(\mathrm{C}_{\mathrm{M}}\right)$ was found to be the most effective in improving the initial reversible capacity and initial coulombic efficiency of coal-based coke powder. After coating with the pitch-based carbon layer, the initial irreversible capacity of coke powder reduced from $87.5 \mathrm{mAh} / \mathrm{g}$ to $65.3 \mathrm{mAh} / \mathrm{g}$, and the initial coulombic efficiency significant improved from $78.5 \%$ to $84.3 \%$. Scanning electron microscopy (SEM) and X-ray diffraction (XRD) were then employed to investigate the samples, the effects of surface modification on the formation of the solid electrolyte interphase (SEI) and the corresponding irreversible capacity losses were discussed. Finally, the influence of the mass contents of pitch powder on the morphology and electrochemical performance of the sample $C_{M}$ were analyzed.
\end{abstract}

Keywords: lithium ion batteries; pitch powder; coal-based coke powder; surface modification; electrochemical properties.

\section{$\underline{\text { FULL TEXT }}$}

(C) 2018 The Authors. Published by ESG (www.electrochemsci.org). This article is an open access article distributed under the terms and conditions of the Creative Commons Attribution license (http://creativecommons.org/licenses/by/4.0/). 